\title{
CHARACTERIZATION OF CRACKS IN HISTORICAL BUILDINGS USING IMAGE-PROCESSING TECHNIQUES
}

\author{
P. L. PÓRCEL ${ }^{1 *}$, B. CASTAÑEDA ${ }^{1}$, R. AGUILAR ${ }^{1}$ \\ ${ }^{1}$ Engineering Department, Civil Engineering Division \\ Pontificia Universidad Católica del Perú \\ Av. Universitaria 1801, Lima, Perú \\ e-mail: \{pporcel, raguilar\}@pucp.pe, castaneda.b@pucp.edu.pe
}

(*corresponding author)

Keywords: Crack Monitoring, Image Processing, Masonry structures.

\begin{abstract}
Cracks are structural pathologies that affect the structural integrity of historical buildings. The methodologies commonly used to detect cracks are based on visual inspections or in intrusive techniques that involve removing external wall layers. The main objective of this study is to develop and validate a semi-automatic and non-destructive tool that helps the user to analyze the position and growth of the cracks in masonry constructions based on a photogrammetry analysis. The developed tool uses image processing to plot a curve of the crack area, and, in case needed, its evolution over time. The tool was validated in laboratory using earthen samples that were subjected to uniaxial compression tests. The research also provides the results of the tool used in a case study of a $16^{\text {th }}$ Century stone masonry church located in the main square of Cusco; Southern Peru. This case study validates the qualitative metrics of the present work, and indicates that the tool provided accurate results when compared to the ground truth, which could be helpful in future research studies in order to automatize crack monitoring.
\end{abstract}

\section{INTRODUCTION}

When the Spanish arrived to Peru, they started the evangelization process, that was done among others, by replacing sites that were sacred to the Inca culture, with churches to impose Christianity. Therefore, destroying partially or fully the predominant stone structures and introducing an earthen mixture of materials called adobe as the main material. These structural modifications resulted in multiple constructions of adobe and mixed structures combining adobe with stone [1]. In Peru, 30\% of dwellings are built with adobe because the supply materials are low-cost and comfortable. The downside of this material comes from its vulnerability to the destructive effect of telluric movements [2]. Structural Health Monitoring of heritage constructions allows researchers to have a better understanding of the current behavior of the structure and it benefits its preservation. Often this procedure requires the installation of many of sensors in order to extrapolate the global behavior of the structure and process that information about the anomalies present in the structure [3]. Machine Vision technologies have been studying procedures that could benefit Structural Health Monitoring; the most commonly used system consists of an image acquisition device, a computer and an image-processing tool. Using a system like this would allow the user to record how the structure changes through time, therefore allowing the image-processing tool to detect anomalies like cracks as they change in time [4]. 


\section{MACHINE VISION TECHNIQUES}

Machine vision techniques have come as the technological approach for crack detection and monitoring, given that the conventional methods are usually performed by experienced human inspectors who identify and manually draw the crack patterns [5]. Machine vision methodologies mostly use a configuration as shown in Figure 1. This set up consists of the tested structure and targets, the Image Acquisition Device that captures and stores the information in a computer where it is processed with an Image-Processing Tool that is tailored to the specific purpose of the study [4].

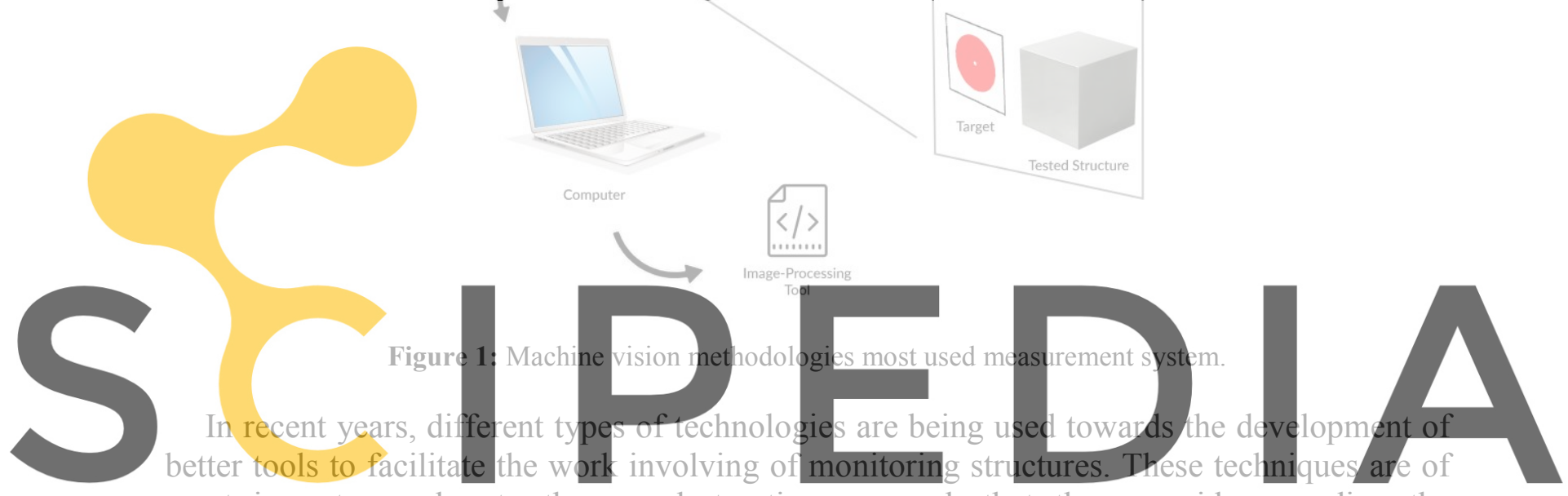

great importance due to the non-destructive approach that they provide regarding the

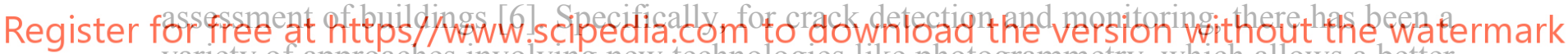
variety of approaches involving new technologies like photogrammetry, which allows a better detection of the targets in order to give more precise quantitative results [7]. In most cases, there is a specimen preparation process that involves the creation and insertion of the targets that would later be used by the image-processing tool to correlate images within the same test or to assess how much has the crack changed [8,9]. Therefore, the creation and selection of the target used is an important step that affects directly the results; however, even more important is the ability to detect and use the information that the target provides to the image-processing tool [10].

\section{DEVELOPMENT OF IMAGE PROCESSING TOOL}

The initial hypothesis of this work is based in the use of tensor voting in order to detect the pixels, that belong to the crack, in an image, by properly analyzing edges between these pixels and the background [11]. This tool was developed with Matlab 2019b, and its Image Processing and Computer Vision toolboxes [12]. First, the images were captured with the acquisition device, in this case a D5000 Nikon camera. Next, the images (Figure 4) were processed by isolating the part of the image where the target is located and then cropping the ROI (Region of Interest). The ROI is used as the area where all the binarization algorithms are performed. 
Initially, a sparse detection of the pixels belonging to the crack is performed by analyzing the overall variation in color between the crack and the background. After that, stick voting is applied to the previously detected pixels to analyze the interaction between them. Finally, the tensor voting algorithm is applied to establish which pixels are proximate enough to others to be part of the crack. On the other hand, the region where the target is contained is processed to detect the red target and extract its measurements. The real measurements of the target are known; therefore, they were compared to the metrics extracted from the previous step. This process allows the tool to obtain a resolution in pixels/meters. Due to human error introduction, the images taken are not entirely parallel to the surface of the specimen, thus, the measure in pixels of the target will not be exactly the same horizontally and vertically, as it should be, given the shape of the target. The final step, consists of calculating the area of the crack in pixels and converting it to meters with the previously calculated resolution.
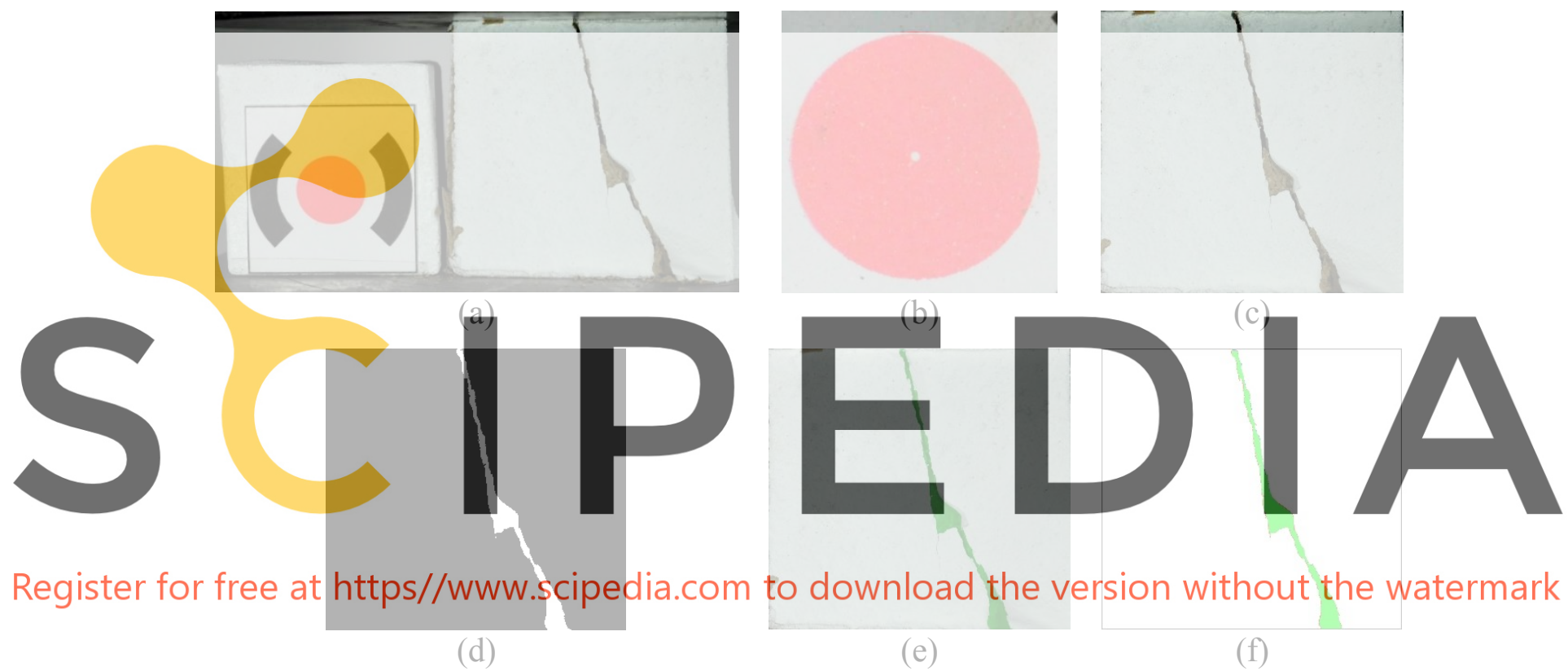

Figure 2: Process that the acquired images follows (a) image acquired (b) target region (c) ROI of the image (d) image after the binarization algorithms (e) final binarization in green over the original ROI in RGB and (f) the comparison between the ground truth and the final binarization.

All of the binarization algorithms use the resolution provided by the target in order to clean the image from little imperfections that could be mistaken by a crack pixel. The user sets the minimum and maximum thickness of the crack, this is very important because it provides the approximate scale of the crack compared to the scale of the image, all the measurements are set in meters. While creating the target the circle was selected, because it is an easy shape to detect and it fits in a rectangle, therefore the horizontal diameter and vertical diameter would be given by the size of the rectangle that wraps it. The red color for the circle was selected because in an RGB image it is easier to eliminate any of its primary colors (red-R, green-G, blue-B). The first part of the detection of the target allows the user to select where the target is, it does not have to be precise because, the algorithm detects only round objects, after that, a bounding box is stablished and later used for the calculation of the resolution in pixel $/ \mathrm{m}$. This part of the process 
is straightforward but it is taken into account that the camera might not be directly parallel to the surface of the specimen, thus, whereas the actual measurements of the circle are the same vertically and horizontally this is not necessarily the case with the measurements of the bounding box. Therefore, this step calculates the vertical and horizontal resolution.

The algorithm starts to process only the last image in the database, in order to get the fully formed crack and goes backwards from there. This helped reduced the errors regarding sudden detachment of adobe that could introduce error in the segmentation. The first step to find crack pixels consists in a binarization where the threshold was calculated according to where did the most difference in color occurred by gray value. A Laplacian $3 \times 3$ kernel was used to do a local convolution and stablish local differences between the neighbor pixels. After that, the differences where added up according to its corresponding gray value. The first binarization is performed using the gray value with the most difference and a binary image with the initial crack pixels is obtained. After this process, Tensor Voting is applied to the binary image that shows the sparse set of pixels belonging to the crack. Tensor voting uses a proximity vote, which allows pixels close to each other to have a stronger vote, therefore, the further a way they are the weaker the vote. This allows to easy rule out the noise that could be introduced into the image for various reasons.

Lastly, the area is extracted at every stage for each specimen, obtaining the graphics that could be analyzed later to see the relation between the load and the change of area. This process consists on another vote in a 4 neighborhood, which assigns the area of 1 to a pixel that is fully surrounded by 4 crack pixels. Thus, gatheri horizontal and vertica the actual area in meters monitoring process invol specimen.

4 VALIDATION IN LABORATORY
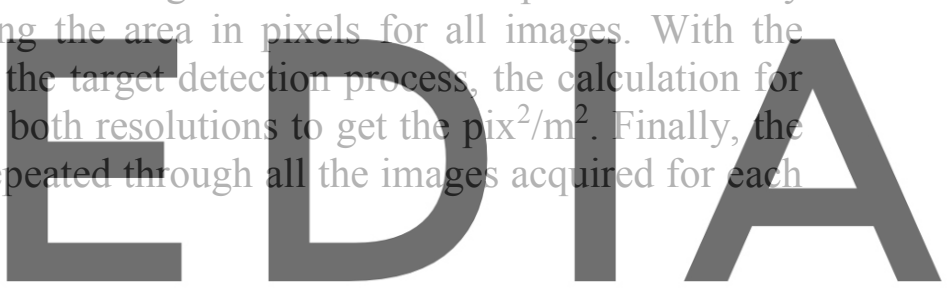
Register for free at https//www.scipedia.com to download the version without the watermark

This research used the C109 standard by ASTM to elaborate the specimens for the data base, even though this standard is set for cement mortars [13], it is used for adobe in this case because of the lack of any international standards referring to compression tests in adobe. Therefore, the specimens used in this first stage where made in cubic molds of $50 \mathrm{~mm}$ per side, the proportions used to get an stabilized earthen mixture were $60 \%$ of natural soil earth and $40 \%$ of sand. The added water needed to be between the $8 \%$ or $9 \%$ of the total weight of the previous mix [14]. However, the mentioned proportion of water was used to build compressed blocks in a compression machine, so for this process the water used was between $10 \%$ and $20 \%$. For the present paper there were 10 specimens evaluated, all the samples were tested in a MTS E45 compression machine until the crack became a rupture compromising the integrity of the block.

The acquisition system used in this process is consistent with the machine vision methodologies used in recent years. In Figure 3, there is a representation of the layout configuration for the compression tests that were performed in the specimens to generate the cracks that would be evaluated later. In this layout, a set of two stereo lights was used to enhance the illumination inside the compression machine as its structure introduced shadows that would pollute the acquisition of data. The camera captures the images with a resolution of $12 \mathrm{MP}$ 
(4288x2848), it was set at a distance of $45 \mathrm{~cm}$ from the specimen with the lenses approximately parallel to the surface of the specimen. A separate program was created in Arduino for the acquisition of data to obtain the pictures automatically while running the compression test. Therefore, we obtained a different number of images per specimen, because the time of rupture was moderately different. The Arduino was connected to a Surface tablet in order to stop the acquisition when the compression test finished. After that, all the images where introduced in a computer where each data base went through an automatic organization process, that would help later with the image processing tool developed in this work.

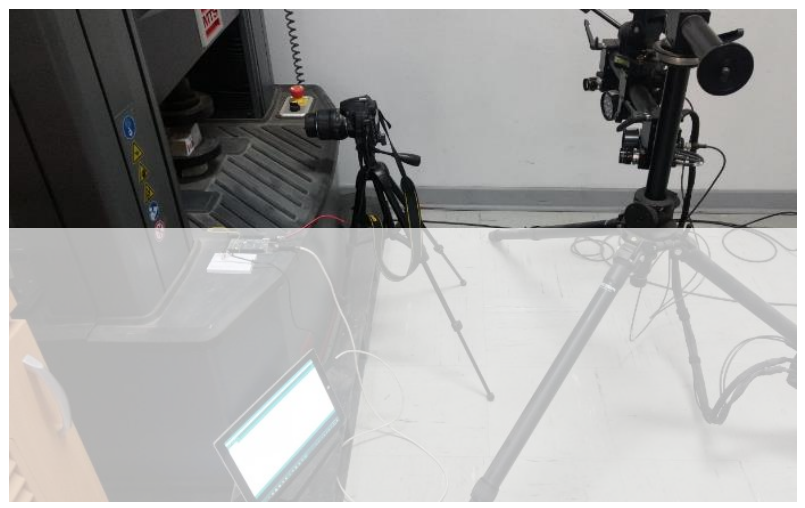

Figure 3: Data acquisition system layout.

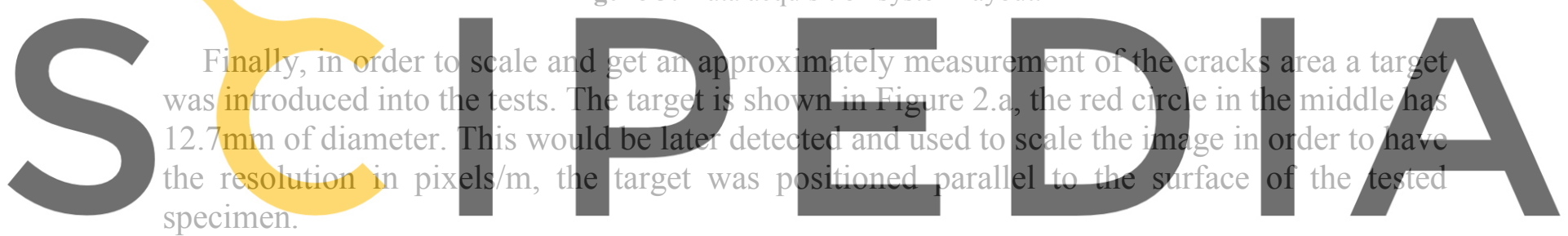

Register fon frestatshttps//www.scipedia.com to download the version without the watermark

The qualitative results of this methodology are given by the Intersection over Union (IoU) metric which measures the intersection of the pixels detected and the pixels provided by the ground truth over the union of the same groups. Considering, that the pixels that are part of a crack do not represent more than $20 \%$ of the images, the accuracy would not be the best fit for a qualitive metric for the results given by the present tool. The IoU metric of each of the ground truths for all the specimens is given in Table 1, which shows that the IoU for the first frame in almost all the tests is $0.0 \%$, this is because the first frame does not have any cracks, therefore, the ground truth does not have any pixels to be compared with. However, during the tests, specimen 4 did have some visible cracks that where drawn on the ground truth but since their thickness is lower that the resolution of the tool its segmentation does not show optimal results. Moreover, specimen 2 did not have any cracks shown until after the frame corresponding to the second ground truth, therefore, its IoU in the second column shows a $0.0 \%$. Accordingly, the column corresponding to the second ground truth, mostly represent cracks that could be below the $1 \mathrm{~mm}$ thickness required to be detected. Finally, the columns that show the ground truths 3 and 4 provide a good result given the resolution condition. 
Pórcel, P., Castañeda, B. and Aguilar, R.

Table 1: Qualitative metric IoU percentage obtained by the comparison of the tools output and the ground truth of every specimen.

Intersection over Union (IoU)

\begin{tabular}{|c|c|c|c|c|}
\hline Ground Truths & 1 & 2 & 3 & 4 \\
\hline Specimen 1 & $0.0 \%$ & $74.0 \%$ & $85.3 \%$ & $92.1 \%$ \\
\hline Specimen 2 & $0.0 \%$ & $0.0 \%$ & $70.9 \%$ & $91.0 \%$ \\
\hline Specimen 3 & $0.0 \%$ & $67.6 \%$ & $79.2 \%$ & $78.4 \%$ \\
\hline Specimen 4 & $13.9 \%$ & $58.5 \%$ & $65.2 \%$ & $84.8 \%$ \\
\hline Specimen 5 & $0.0 \%$ & $78.6 \%$ & $84.9 \%$ & $85.5 \%$ \\
\hline Specimen 6 & $0.0 \%$ & $70.3 \%$ & $84.1 \%$ & $90.2 \%$ \\
\hline Specimen 7 & $0.0 \%$ & $51.1 \%$ & $79.9 \%$ & $87.4 \%$ \\
\hline Specimen 8 & $0.0 \%$ & $83.3 \%$ & $79.9 \%$ & $79.2 \%$ \\
\hline Specimen 9 & $0.0 \%$ & $82.4 \%$ & $84.5 \%$ & $90.3 \%$ \\
\hline Specimen 10 & $0.0 \%$ & $84.9 \%$ & $87.3 \%$ & $90.1 \%$ \\
\hline
\end{tabular}

In Figure 5, it is shown the result of the comparison between the Ground Truth segmentation to the one realized by the tool in two specimens. The color green represents the accurate segmentation of the crack, the color red provides information about the false negative pixels and lastly the color blue displays the false positive pixels. For each test, four ground truth

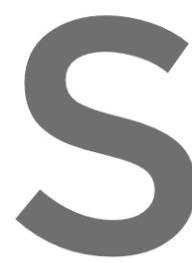
images were created in segmentation was perfor and was done pixel by
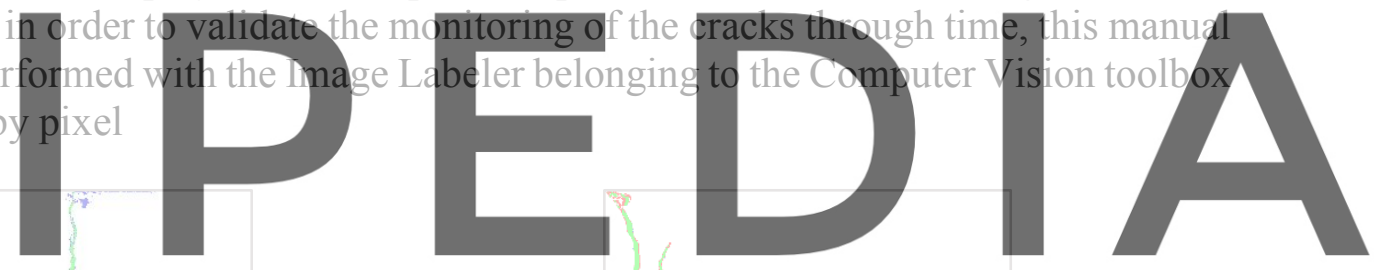

Register for free at https//www.scipedia.com to download the version without the watermark

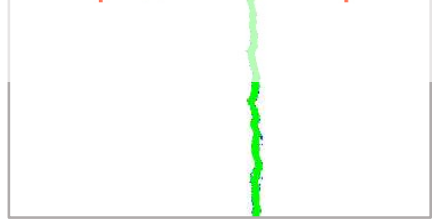

(a)

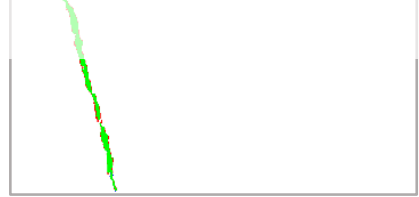

(b)

Figure 4: (a) Comparison of the proposed segmentation with the ground truth in the last frame of specimen 3 and (b) Comparison of the proposed segmentation with the ground truth in the last frame of specimen 5.

The quantitative results of the tool are provided by the change in the crack's area produced through time. Thus, each row in Figure 5, represent different frames in time while the crack in each specimen starts to grow. The first column represents the first frame where no crack was previously formed. The next column corresponds to the $150^{\text {th }}$ image for each specimen in this part both adobe cubes where still on the elastic deformation region. Specimen 2 shows cracks but little segmentation, this is because the cracks in that image are thinner than $1 \mathrm{~mm}$ which is the minimum thickness that the tool perceives. The third column shows the image in the elastic limit point where the adobe cubes enter the plastic deformation region and the crack starts growing faster. The last column the last frames of each test. 


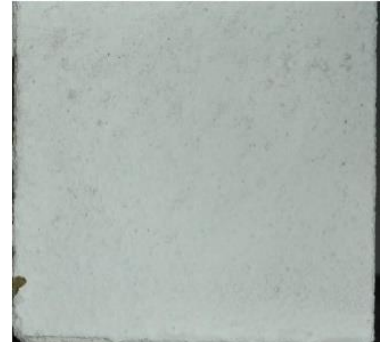

(a)

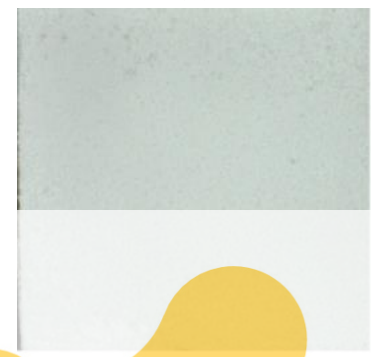

(e)

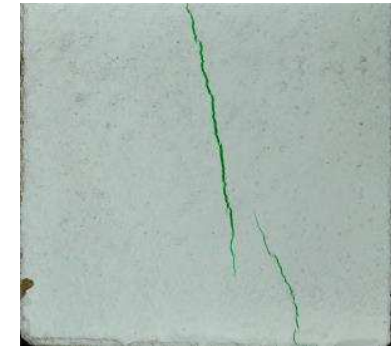

(b)

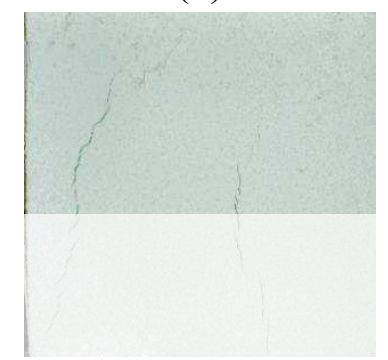

(f)

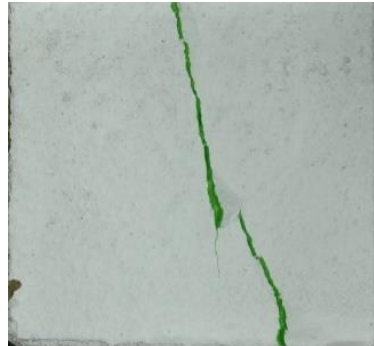

(c)

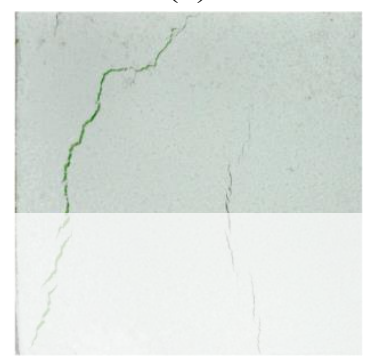

$(g)$

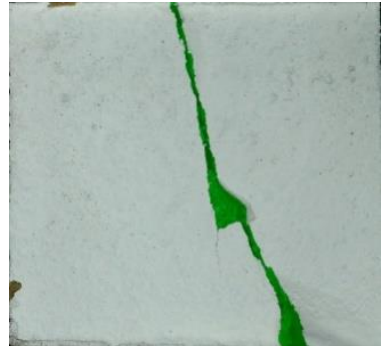

(d)

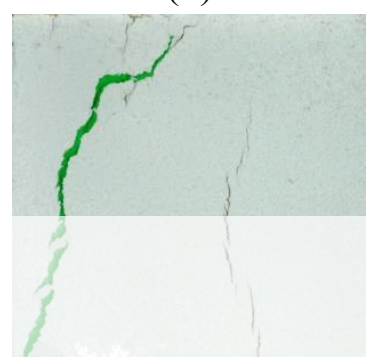

(h)

Figure 5: Images that represent how does the crack changes (a) first image of specimen 1, (b) image 150 of specimen 1, (c) image 293 of specimen 1, (d) last image of specimen 1,(e) first image of specimen 2, (f) image 150 of specimen 2, (g) image 273 of specimen2 and (h) last image of specimen 2.

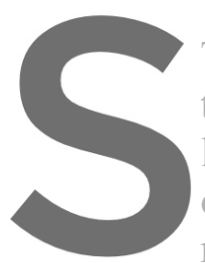

The results of the first 5 the change of the area vers

etter indices correspond to the frame the

of the tests for Specimen
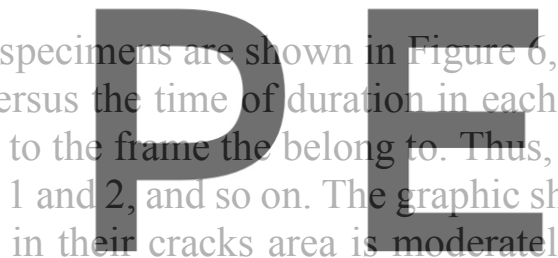

, whic
, Figu
hows
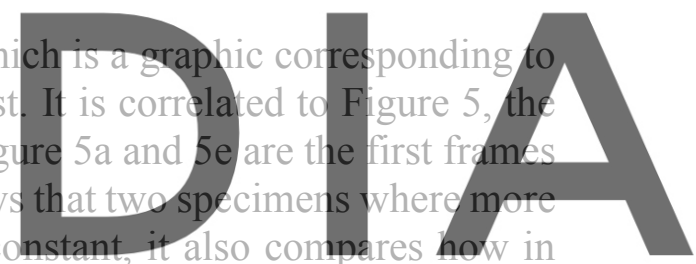

some specimens the area of the crack is substantially bigger. The points "c" and "g" correspond

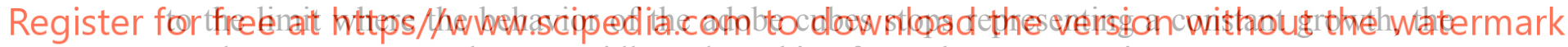
crack's area starts to change rapidly and reaching faster the rupture point.

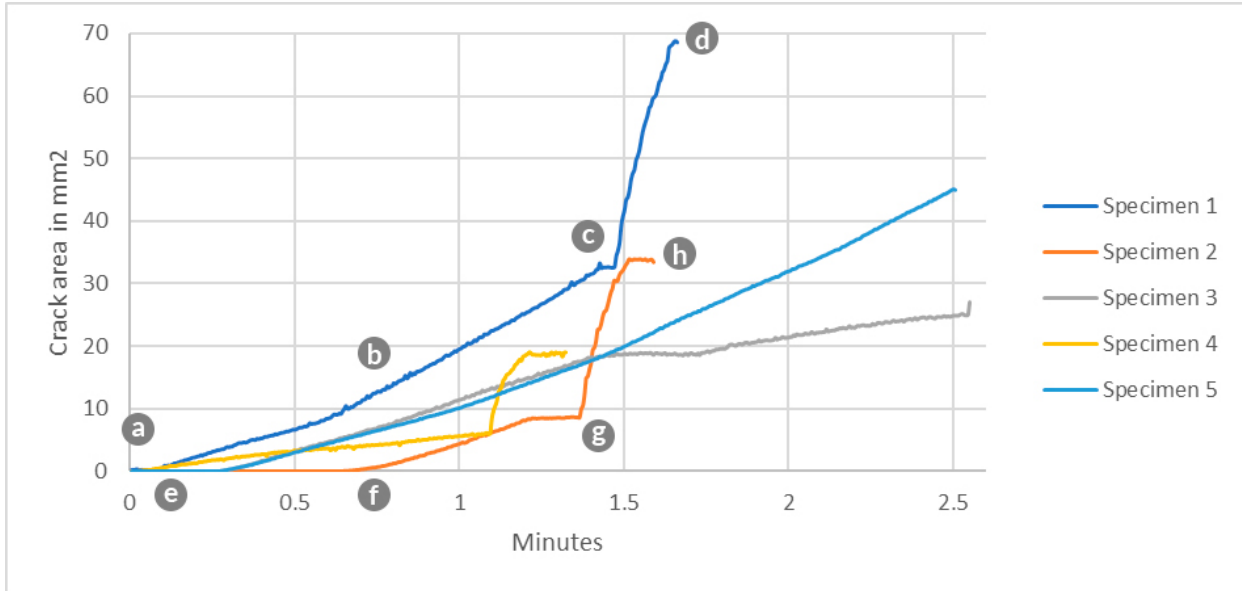

Figure 6: Graphic of the change in area of the cracks in the first 5 specimens through the duration of the tests. 


\section{VALIDATION IN A HISTORICAL STONE MASONRY CHURCH}

The case study evaluated in this paper is focused on an important heritage building, which is part of the Andean Baroque Route, composed of four representative churches of Cusco, Peru. The Church of the Society of Jesus, was built in 1576 over the Inca temple called Amaru Cancha, however, it suffered the consequences of the 1650 earthquake and had to be re-built in 1651. In this occasion, it was contemplated with three doors facing the main square; the main vault was finished and closed in august of 1653. In 1950, another earthquake caused damage mainly in the structures of the façade and choir. The structure was rebuilt in a Latin cross shape, its façade, shown in Figure 7.a, is made of profusely decorated stone and it has two bell towers and two external chapels.

This research was part of a project for the Structural Health Assessment of the church. In order to know the current state of the building image registration was performed. Consequently, cracks and humidity spots on the inside and outside of the church were registered. A great number of cracks was found in the façade, therefore, a large number of images was collected. The pictures shown in Figure 7.a and 7.b, were some of the most representatives within the research. In order to assess the cracks in this structure these pictures were evaluated with the tool provided by the research on this paper. Particularly, for this evaluation it was not possible to use the target. However, the results obtained validate the accuracy of the test using the IoU metric.
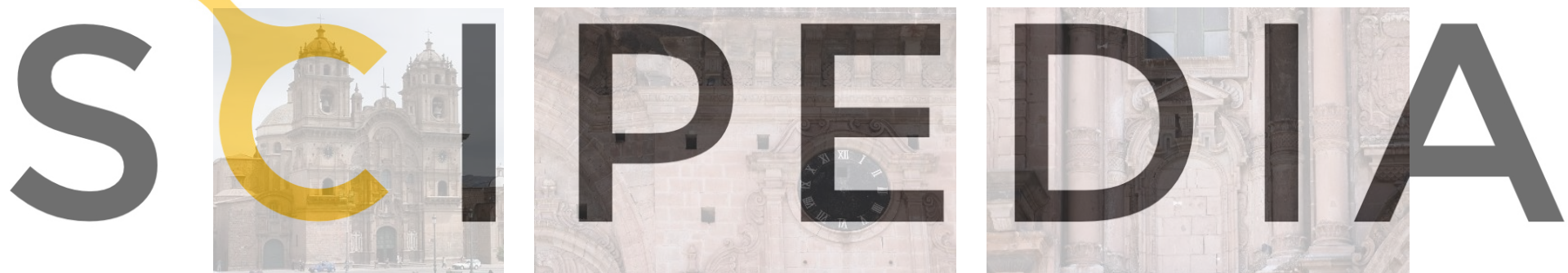

Register for free at httjps//www.scipedia.con(B) to download the version weithout the watermark

Figure 7: (a) The church of the Society of Jesus, (b) right bell tower and (c) left side of the façade.

\subsection{Results}

The qualitative results are shown in Table 1, which confirm that the great variations in contrast that the façade has play against the capabilities of the presented tool. However, the results do not correspond to a poor segmentation, it is also seen in Figure 8 how some junctions are not detected as cracks.

Table 2: Qualitative results for two pictures from Figure 9.

\begin{tabular}{cccc}
\hline & $\mathbf{1}$ & $\mathbf{2}$ & $\mathbf{3}$ \\
\hline IoU & $56.3 \%$ & $61.1 \%$ & $55.5 \%$
\end{tabular}

In Figure 8, the results of the tool being used are shown in the images obtained of the representing cracks of the façade of the church. Due to, the large variation in color in the façade 
the use of the tool was performed in parts as its shown in Figure 8, the first two columns represent parts of the same image, in this case the full image is presented in Figure 9.b. The third column of Figure 8 represents another part of the façade, in this case only one section had visible cracks, the full image is presented in Figure 9.b. In the second column belonging to Figure 8, it is shown how some parts of the borders and shadows introduced become false positives for the tool being represented in blue. Moreover, in Figure 8.f, some cracks that were not detected represent cracks of a thickness below the proportional minimum, given that these images represent a bigger surface than the adobe cubes previously tested.

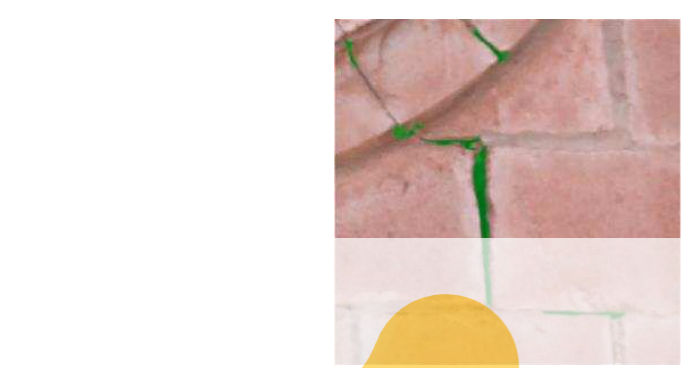

(a)

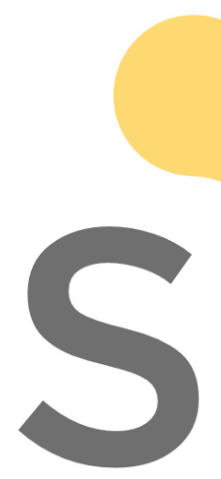

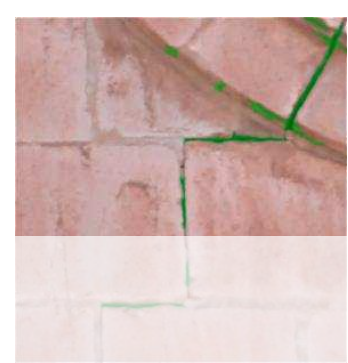

(b)

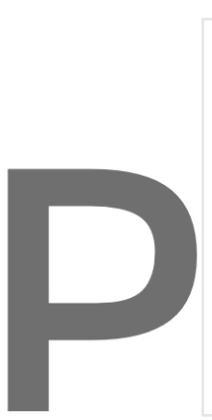

(d)

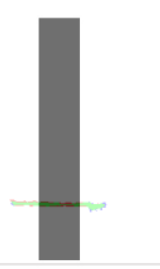

$1 /$

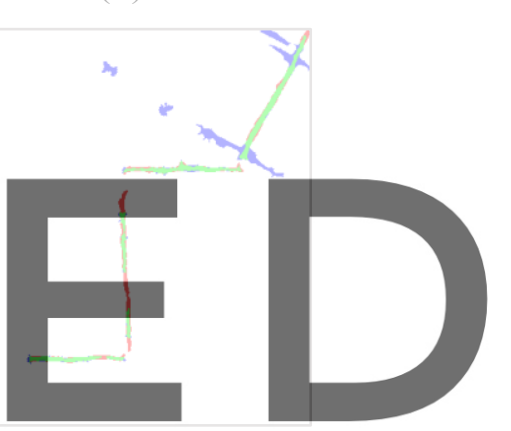

(e)

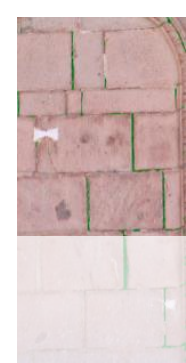

(c)

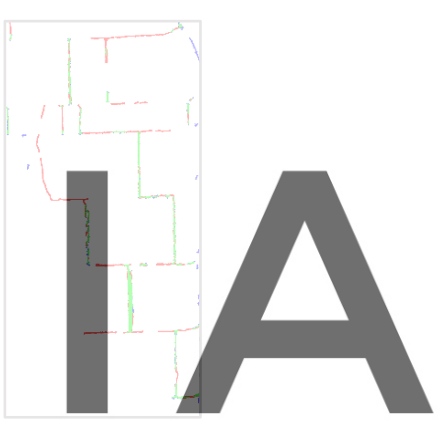

(f)

Figure 8: (a), (c) and (e) are the segmentation in green over the ROI, (b), (d) and (f) are the qualitative result of the tool from different cracks on the façade of the Society of Jesus.

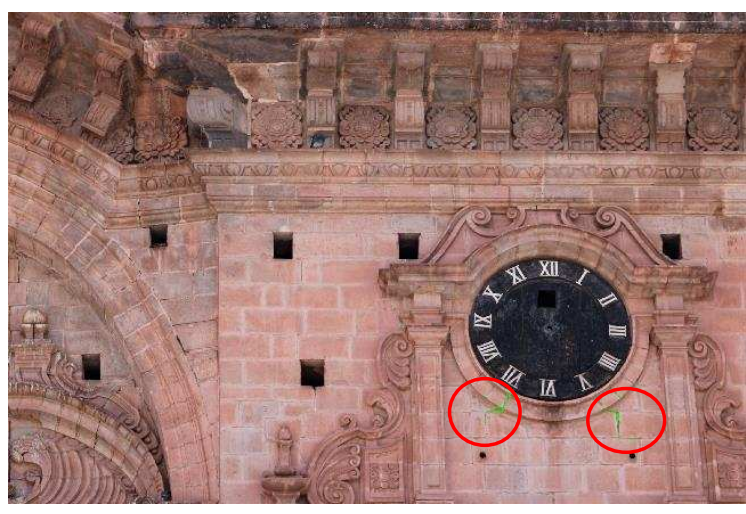

(a)

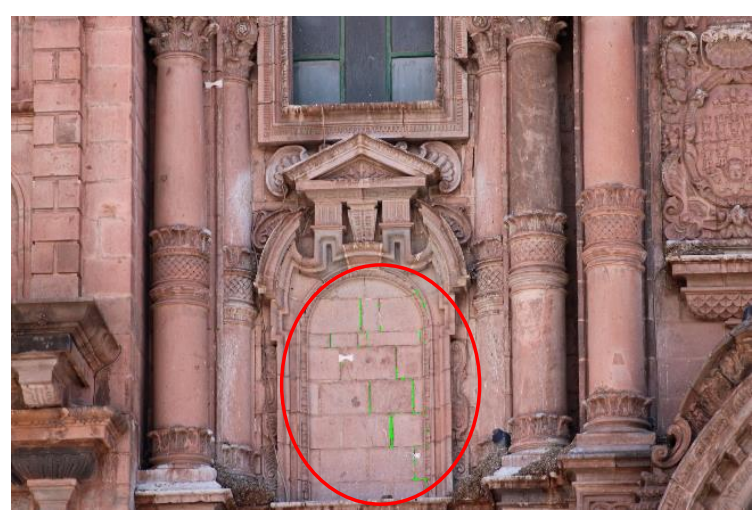

(b)

Figure 9: (a) Image 1 of the top part of the façade, (b) Image 2 of the middle part of the façade. 


\section{CONCLUSIONS}

The results in this research show that the tool developed has high accuracy in segmenting the crack selected in order to perform a geometric characterization to get the crack's area and see how it changes trough time. This feature is the key contribution of this research, because it provides a tangible measurement of the change the crack suffers in time. For the field of civil engineering and real estate business, it is of upmost importance to control cracks as they start to form in order to assess if the crack will become a danger to the integrity of the studied building.

Therefore, it can be used in studies regarding cracks that could potentially become a great danger, the change in the area could become a red flag if it starts to increase rapidly compared to the rest of the monitored time.

Acknowledgements. Engineering and Heritage Laboratory at PUCP performed this research. The authors acknowledge the funding provided by STIC Amsud in the framework of the project entitled "Development of STIC tools for the structural diagnosis of heritage constructions", that has been a collaborative project of the University of Orleans, the University of Chile and PUCP. The authors also acknowledge the funding provided by DGI-PUCP in the framework of the project No 2019-0- 0004

\section{REFERENCES}

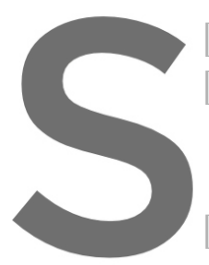
R. Segre, Americ L Latina en su arquitectura,
M. Blondet, M. Serrano, A. Rubiños y E. I
Comunidad Andina en Construcción
Iberoamericano de Arquitectura y Constru
D. Inaudi, A. Rufenacht, B. von Arx, H. P.
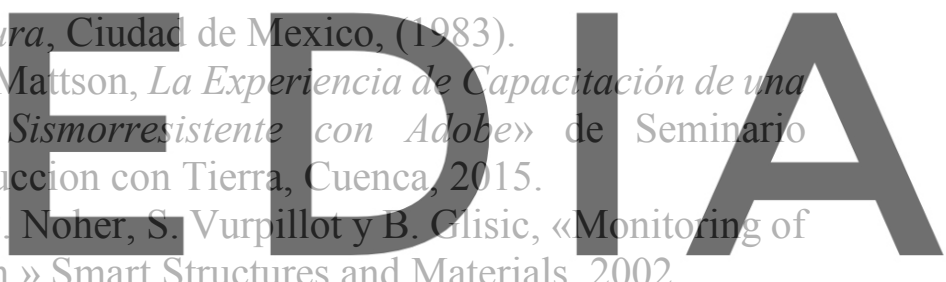
a concrete arch bridge during construction,» Smart Structures and Materials, 2002

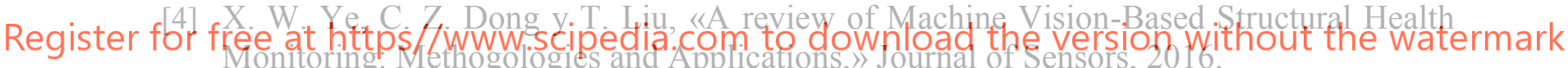
[5] T. Yamaguchi y S. Hashimoto, «Fast crack detection method for large-size concrete surface images using percolation-based image processing,» Machine Vision and Applications, pp. 797-809, 2010.

[6] Z. Chen y T. C. Hutchinson, «Image-Based Framework for Concrete Surface Crack Monitoring and Quantification,» de Advances in Civil Engineering, Hindawi Publishing Corporation, 2010.

[7] J. Valenca, D. Dias-da-Costa, E. Julio, H. Araujo y H. Costa, «Automatic crack monitoring using photogrammetry and image processing,» de Measurement, 2013, pp. 433-441.

[8] W. Benning, J. Lange, R. Schwermann, C. Effkemann y S. Gortz, «MONITORING CRACK ORIGIN AND EVOLUTION AT CONCRETE ELEMENTS USING PHOTOGRAMMETRY,» de TS COMM V: Metrology and Industrial Applications, 2004.

[9] U. Hampel y H.-G. Maas, «Cascaded image analysis for dynamic crack detection in material testing,» ISPRS Journal of Photogrammetry and Remote Sensing, vol. 64, pp. 345$350,2009$.

[10] S. Nishiyama, N. Minakata, T. Kikuchi y T. Yano, «Improved digital photogrammetry technique for crack monitoring,» de Advanced Engineering Informatics, 2015. 
[11] G. Medioni, C.-K. Tang y M.-S. Lee, «Tensor Voting: Theory and Applications».

[12] The Mathworks, «MATLAB, Image Processing Toolbox and Vision Computer Toolbox,» Natick, 2019.

[13] A. International, Standard Test Method for Compressive Strength of Hydraulic Cement Mortars (Using 2-in. or [50-mm] Cube Specimens), Philadelphia, 2019.

[14] S. Y. Alvarez Ordoñez, «COMPARACIÓN DE LAS PROPIEDADES MECÁNICAS DE UNIDADES Y PRISMAS DE BLOQUES DE TIERRA COMPRIMIDA ESTABILIZADA CON CEMENTO Y GEOPOLÍMERO DE PUZOLANA,» PUCP, Lima, 2018.

[15] L. E. Yamin Lacouture, C. Philips Bernal, J. C. Reyes Ortiz y D. Ruiz Valencia, «Estudios de vulnerabilidad sismica, rehabilitacion y refuerzo de casas en adobe y tapia pisada,» de APUNTES, 2007, pp. 286-303.

[16] G. K. Velarde Abugattas, «ANÁLISIS DE VULNERABILIDAD SÍSMICA DE VIVIENDAS DE DOS PISOS DE ADOBE EXISTENTE EN LIMA,» Lima, 2014. 